\title{
RUNX1-Evi-1 fusion gene inhibited differentiation and apoptosis in myelopoiesis: an in vivo study
}

\author{
Lijing Shen $^{1 \dagger}$, Jianyi Zhu ${ }^{1 \dagger}$, Fangyuan Chen ${ }^{2 *}$, Wenjie Lin ${ }^{1}$, Jiayi Cai ${ }^{1}$, Jihua Zhong ${ }^{1}$ and Hua Zhong ${ }^{1}$
}

\begin{abstract}
Background: Acute myeloid leukemia (AML) 1-Evi-1 is a chimeric gene generated by the t $(3 ; 21)$ (q26; q22) translocation, which leads into malignant transformation of hematopoietic stem cells by unclear mechanisms. This in vivo study aimed to establish a stable line of zebrafish expressing the human RUNX1-Evi-1 fusion gene under the control of a heat stress-inducible bidirectional promoter, and investigate its roles in hematopoiesis and hematologic malignancies.
\end{abstract}

Methods: We introduced human RUNX1-Evi-1 fusion gene into embryonic zebrafish through a heat-shock promoter to establish Tg(RE:HSE:EGFP) zebrafish. Two males and one female mosaic F0 zebrafish embryos (2.1\%) were identified as stable positive germline transgenic zebrafish.

Results: The population of immature myeloid cells and hematopoietic blast cells were accumulated in peripheral blood and single cell suspension from kidney of adult Tg(RE:HSE:EGFP) zebrafish. RUNX1-Evi-1 presented an intensive influence on hematopoietic regulatory factors. Consequently, primitive hematopoiesis was enhanced by upregulation of gata2 and scl, while erythropoiesis was downregulated due to the suppression of gata1. Early stage of myelopoiesis was flourishing with the high expression of pu.1, but it was inhibited along with the low expression of mpo. Microarray analysis demonstrated that RUNX1-Evi-1 not only upregulated proteasome, cell cycle, glycolysis/ gluconeogenesis, tyrosine metabolism, drug metabolism, and PPAR pathway, but also suppressed transforming growth factor $\beta$, Jak-STAT, DNA replication, mismatch repair, p53 pathway, JNK signaling pathway, and nucleotide excision repair. Interestingly, histone deacetylase 4 was significantly up-regulated. Factors in cell proliferation were obviously suppressed after 3-day treatment with histone deacetylase inhibitor, valproic acid. Accordingly, higher proportion of G1 arrest and apoptosis were manifested by the propidium iodide staining.

Conclusion: RUNX1-Evi-1 may promote proliferation and apoptosis resistance of primitive hematopoietic cell, and inhibit the differentiation of myeloid cells with the synergy of different pathways and factors. VPA may be a promising choice in the molecular targeting therapy of RUNX1-Evi-1-related leukemia.

Keywords: RUNX1-Evi-1, Zebrafish, Myelopoiesis, Apoptosis, Valproic acid

\section{Background}

RUNX1-Ecotropic viral integration site (Evi)-1 chimeric gene is generated by the $\mathrm{t}(3 ; 21)(\mathrm{q} 26 ; \mathrm{q} 22)$ translocation and plays a pivotal role in progression of different hematopoietic stem cell malignancies [myelodysplastic syndrome (MDS), chronic myelogenous leukemia to acute

\footnotetext{
* Correspondence: chenfangyuan62@163.com

${ }^{\dagger}$ Equal contributors

2Department of Hematology, Ren Ji Hospital, School of Medicine, Shanghai Jiao Tong University, 160 Pujian Road, Shanghai, China
}

Full list of author information is available at the end of the article blastic crisis phase, and acute myelogenous leukemia (AML)]. RUNX1, also named AML1, is essential for hematopoietic cell development in fetal liver as well as lineage-specific differentiation in adult liver. Point mutations of RUNX1 are relatively common in M0AML (12-33 \%), MDS (23\%), and therapy-related and radiationassociated MDS/AML (38-46 \%) [1]. Evi-1 is a nuclear transcription factor that plays an essential role in the regulation of hematopoietic stem cells. Aberrant expression of Evi-1 has been reported in up to $10 \%$ of patients with

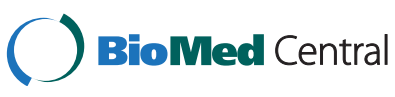

(c) 2015 Shen et al. Open Access This article is distributed under the terms of the Creative Commons Attribution 4.0 International License (http://creativecommons.org/licenses/by/4.0/), which permits unrestricted use, distribution, and reproduction in any medium, provided you give appropriate credit to the original author(s) and the source, provide a link to the Creative Commons license, and indicate if changes were made. The Creative Commons Public Domain Dedication waiver (http://creativecommons.org/publicdomain/zero/1.0/) applies to the data made available in this article, unless otherwise stated. 
AML, which can predict poor outcome as a diagnostic marker [2]. However, bone marrow cells of murine transduced with Evi-1 alone cannot cause leukemia [3], while deletion of RUNX1 alone does not immortalize bone marrow cells [4], which suggest that both suppression of RUNX1 and activation of Evi-1 are required for RUNX1-Evi-1 leukemogenesis. It could be assumed that RUNX1-Evi-1 shares several molecular processes with wild-type Evi-1 and RUNX1 is more widely expressed in hematopoietic cells than Evi-1, it causes activation of Evi-1 function in hematopoietic cells, thus enhance cellular proliferation.

Evi-1 protein has two separate $\mathrm{Cys}_{2} \mathrm{His}_{2}$-type zinc finger domains. In RUNX1-Evi-1 chimeric protein, the N-terminal half of RUNX1 including a runt homology domain (RHD) is fused to the entire zinc-finger Evi-1 (Fig. 1). Takeshita et al. demonstrated that the entire sequence of Evi-1 was required for transformation of primary bone marrow leukemia cells by RUNX1-Evi-1 [5]. Mice transplanted with RUNX1-Evi-1 retroviral transduced bone marrow cells suffered from an AML 5-13 mo after transplantation. The disease could be readily transferred into secondary recipients with a much shorter latency [6]. In another distinct BMT mouse model, Evi-1 seemed to collaborate with an RUNX1 mutant harboring a point mutation in the Runt homology domain (D171N) to induce with an identical phenotype characterized by marked hepatosplenomegaly, myeloid dysplasia, leukocytosis, and biphenotypic surface markers [7]. However, all of these sick mice died soon after transplantation, and generation of transgenic offspring to carry on the follow-up study is impossible.

Zebrafish (Danio rerio) hematopoiesis shows anatomic, physiologic, and genetic conservation with that of humans [8]. Furthermore, ectopic expression of human or murine oncogenes driven by specific promoters in zebrafish has been shown to faithfully develop leukemia closely parallel to the human leukemia subtypes [9]. Finally, the efficient reproduction and rapid development of zebrafish embryos allow it to become a convenient model to investigate tumor development and dissemination in real time even without sacrificing the animals.

In this study, we established a stable line of zebrafish expressing the human RUNX1-Evi-1 fusion gene under the control of a heat stress-inducible bidirectional promoter to examine its roles in hematopoiesis and hematologic malignancies. Interestingly, the phenotypes of these fish resembled to those of the human's MDS-RAEB or AML. This transgenic strategy was based on previous studies $[6,10]$.

\section{Methods}

This study was approved by the Institutional Animal Care and Use Committee (IACUC) of Shanghai Research Center for Model Organisms in China (approved ID: 2010-0010).

\section{Plasmid construction}

The cDNA of human AML1(RUNX1)-Evi-1 was identified and obtained from the SKH-1 cell line and inserted into the EcoRI site of pME18S, named as pME-AE (generous gift from Motohi Ichikawa) [5]. It was subcloned into EcoRI and EcoRV (Takara, Japan) sites of the pSGH2 vector [10], which contains eight HSE sequence (AGAAC GTTCTAGAAC) and EGFP segment. Then, we obtain the hRUNX1-Evi-1-HSE-EGFP insert construct (Fig. 2a), HSE allows the symmetrical addition of a CMV minimal promoter to both ends in order to drive the expression of two interested genes (EGFP at one side and hRUNX1-Evi-1 at the other side) flanked by $5 \mathrm{~V}$ and $3 \mathrm{~V}$ globin UTRs and SV40 polyadenylation (pA) signal (I-SceI meganuclease recognition sites) (Fig. 2b).

\section{Generation of the Tg(RE:HSE:EGFP) zebrafish line}

Zebrafish was maintained as described by Westerfield [11]. Developmental stages refer to hours or days post

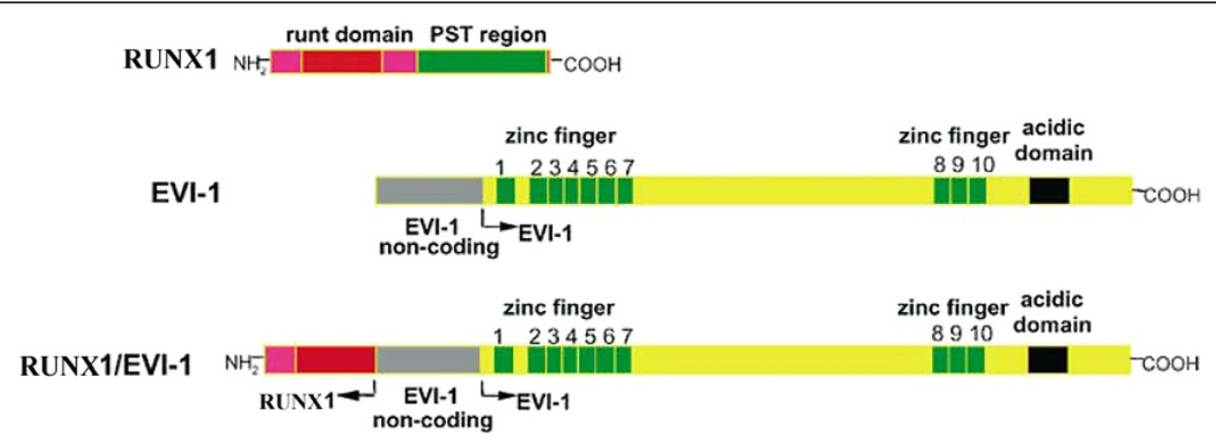

Fig. 1 Schematic structure of wild-type RUNX1, Evi-1 and RUNX1/Evi-1 [30]. Wild-type RUNX1 possesses RHD at the N-terminus and PST region at the C-terminus. In RUNX1/Evi-1, N-terminal RUNX1 sequences are abruptly interrupted at the end of the RHD and followed by almost the entire coding region of Evi-1, including Evi-1 noncoding region, the first zinc finger domain, the second zinc finger domain, and an acidic (acidic amino acid-rich) domain are shown by boxes 


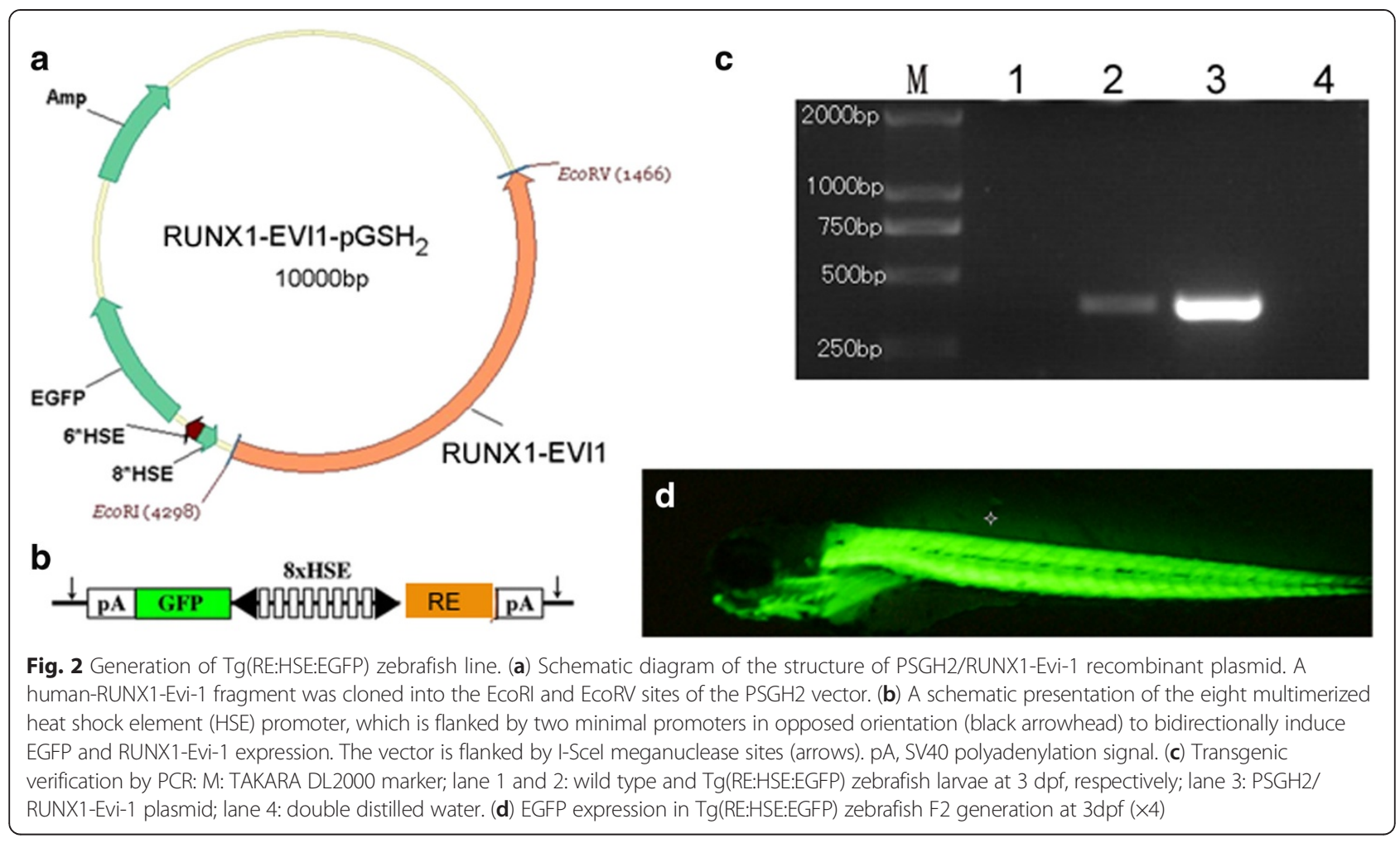

fertilization (hpf or dpf). Fertilized wild type (WT) AB fish eggs were microinjected through the chorion into the cytoplasm at the one-cell stage of development according to our previous work [12]. The pSGH2hRUNX1-Evi-1 plasmid was co-injected with I-SceI meganuclease enzyme (0.5 units/ $\mu \mathrm{L})$ (New England Bio Labs). A pressure injector (IM-300, NARISHIGE) was used with borosilicate glass capillaries. After injection, the embryos were collected in Petri dishes and incubated at $28{ }^{\circ} \mathrm{C}$. Heat shock was executed at $38{ }^{\circ} \mathrm{C}$ for 1 hour at between 14 to $18 \mathrm{hpf}$ to induce EGFP and RUNX1-Evi-1 expression. EGFP+ fish were screened under the fluorescent microscope on the next day and bred up to sexual maturity, then crossed with the WT AB fish. The transgenetic (Tg) offspring also received heat shock for an hour to induce the target genes expression.

\section{Real-time quantitative reverse transcription PCR (qRT-PCR) and western blot analysis}

QRT-PCR was performed as described previously [11]. It was performed using $400 \mathrm{ng}$ of cDNA templates in an ABI StepOnePlus System (Applied Biosystems, USA). PCR primers were designed to span introns and listed in Table 1. Measured cycle threshold $(\mathrm{Ct})$ values represent $\log 2$ expression levels. Each target gene was normalized to $\beta$-actin and calculated using the $2-\Delta \Delta \mathrm{CT}$ method [13]. Deyolking embryos and protein immunoblotting were performed as described [14]. Anti-JNK (No.9252) and anti-actin antibodies were purchased from Cell Signaling
Technology (Beverly, MA). Anti-p-JNK (No.sc-12882) was purchased from Santa Cruz Biotech (USA).

\section{In situ hybridization}

Whole-mount in situ hybridization was performed with digoxigenin-labeled (Roche) antisense riboprobes for hematopoietic transcription factors ( $\mathrm{scl}, \mathrm{lmo} 2$, gata1, pu.1, mpo) according to our previous work [15].

\section{Cytological analysis}

After transferred into $50 \mathrm{mg} / \mathrm{L}$ tricaine for $1 \sim 3 \mathrm{~min}$, blood was harvested from zebrafish by making a lateral incision just posterior to the dorsal fin in the dorsal aorta area and used in preparing blood smears [16]. Slides were then stained with Wright Giemsa stain and examined under oil immersion by light microscopy. Identification of zebrafish peripheral blood cells was based, in part, on previous descriptions of teleost blood cells [17]. Single cell suspensions of kidney were collected and filtered by $40 \mu \mathrm{m}$ mesh, than stained by the same method.

\section{Microarray analysis}

The WT and Tg(RE:HSE:EGFP) F2 generation embryos were heated shocked at $38{ }^{\circ} \mathrm{C}$ for 1 hour at $16 \mathrm{hpf}$, then raised to $3 \mathrm{dpf}$. Total RNAs were isolated with Trizol (Invitrogen). The samples were processed and subsequently analyzed in triplicate on Zebrafish Oligo Microarrays (Agilent Technologies Italia, Italy) which contain 
Table 1 RT-PCR Primers

\begin{tabular}{|c|c|c|c|}
\hline Name & Forward primer & Reverse primer & Product (bp) \\
\hline RUNX1-Evi-1 & ATATCGCTGCGAAGACTGTGACCA & TGAAGGTTGCTAGGGTCCGTGAAA & 381 \\
\hline scl & GAACAGTATGGGATGTATCCTAGC & CGTTGAGGAGCTTAGCCAGA & 265 \\
\hline Imo2 & ACACTGGAGGCAAATGAGGAG & AGTAAAGCCTGCGTCCCACC & 193 \\
\hline gata2 & CTGCCAGACAACCACGACC & CCAGATCGTTTACTCCTCTTGG & 180 \\
\hline gata1 & CCATCGTATTATTCCACCAGC & GGATGTGGGGTTGTAGGGAG & 159 \\
\hline pu.1 & TCCCAGCAGTCGTAGTCCTC & CCATTTCGCAGAAGGTCAA & 141 \\
\hline mpo & GGGTTGACCACGATCTGACT & CAGGGAGACAGGTGTTAGGG & 159 \\
\hline$c-m y b$ & GGCAGAAAGTCCTCAACCC & ATCGGTTTCCAAGTTTCTCG & 252 \\
\hline runx1 & TGGGACGCCAAATACGAAC & AGGACGGAGCAGAGGAAGTT & 227 \\
\hline P21 & GAACGATGTGCTGCACTCCC & TGTCAATAACGCTGCTACGAGAC & 236 \\
\hline P27 & CGACTGTAGGGTAACGGAGCA & GGGTGTCGGACTCAATGGTT & 178 \\
\hline P53 & CGGCGATCATGGATTTAGGC & TTCAGCCACATGCTCGGACT & 202 \\
\hline ras & GTCCACGATGAATCCCGAATA & TCTCCTGCCCTGCTGTATCC & 212 \\
\hline Bax & ACAGGGATGCTGAAGTGACC & GAAAAGCGCCACAACTCTTC & 236 \\
\hline $\mathrm{BCl} 2$ & AACGCGAATTTGAGGAAATG & TATCTACCTGGGACGCCATC & 189 \\
\hline JNK & AACAGGAATAAGCGCGAGAA & TTGTGGTTGACGCATTTCAT & 245 \\
\hline JUN & AAACAGCGCTTTCTCTCAGC & TGATCATGCCGTTGCTAGAC & 221 \\
\hline skp2 & ATCTGGGACTGAGCCGTTGT & GAGAACGGCTGCGTGTTGAT & 166 \\
\hline Caspas3 & AGGCTTGTCGAGGAACAGAA & CATGATCTGCAAGAGCTCCA & 233 \\
\hline smad7 & GGTTCTGTGCCTGCTTCCA & TGCCCTGAGGTAGGTCGTAGA & 202 \\
\hline smad4 & AGACCTCCACATACCACCACA & GTCCATCTCGAAGTAGGCAAT & 221 \\
\hline$\beta$-actin & CCTGACCGAGAGAGGCTACA & CGCAAGATTCCATACCCAAG & 242 \\
\hline
\end{tabular}

43,554 sets of probes. The microarrays were scanned in an Agilent DNA Microarray Scanner and the images were processed using Feature Extraction software. Functional annotation analysis was performed using NIH-DAVID software (version 6.7) to find the most relevant Kyoto Encyclopedia of Genes and Genomes (KEGG) terms associated with differentially expressed genes (DEGs) [18]. For this purpose, the significance p-value threshold was set as $<0.01$, with Bonferroni multiple testing correction $(<0.01)$.

\section{Drug administration}

Valproic acid (VPA, CAS Number: 1069-66-5, SigmaAldrich Co. LLC., USA) was dissolved with DMSO and then diluted into different concentrations of $5,10,25$, 50, 100, 250, $500 \mu \mathrm{M}$ (DMSO $<0.2 \%$ in each to avoid the toxicity of DMSO [19]) in egg water. 30 embryos were maintained in individual wells in 12-well microtitre plates at $28{ }^{\circ} \mathrm{C}$ from $14 \mathrm{hpf}$. At 24 and $48 \mathrm{hr}$ after VPA treatment, larvae were collected for LD50 confirmation and gene screen.

\section{FACS profile analysis}

$\mathrm{Tg}$ (RE:HSE:EGFP) larvae were crushed and cell suspensions were homogenized in ice-cold $0.9 \times$ phosphatebuffered saline (PBS) containing $5 \%$ fetal bovine serum, and then passed through a $40 \mu \mathrm{m}$ filter to obtain a single cell suspension. These single cells treated with red blood cell lysis solution and washed once with PBS, stained with Propidium Iodide (Sigma-Aldrich) at a final concentration of $1 \mu \mathrm{g} / \mathrm{mL}$ and analyzed by fluorescenceactivated cell sorting (BD FACS ARIA II SORP, USA) to investigate apoptosis in RUNX1-Evi-1 positive cells.

\section{Statistical analysis}

Data were analyzed on GraphPad Prism 5 using one-way ANOVA and unpaired Student's t test. Differences were considered significant at $\mathrm{p}$ values of less than 0.05 .

\section{Results}

\section{Establishment of Tg(RE:HSE:EGFP) zebrafish line}

About $40 \%$ of the embryos injected with the pSGH2RUNX1-Evi-1 plasmid exhibited EGFP+ expression after heat shock at $38^{\circ} \mathrm{Cfor}$ an hour. The adult EGFP+ fish was crossed with the WT fish. The Tg(RE:HSE:EGFP) F0 founders with the highest germline transmission rate were identified on the basis of fin genotyping (Fig. 2c-d) and EGFP expression of the F1 offspring after the same heat shock treatment. Three of 146 (2.1 \%) mosaic F0 zebrafish were identified as the stable germline Tg zebrafish, including 2 males and 1 female. The Tg F1 generation 
were mated to create homozygous $\mathrm{Tg}(\mathrm{RE}: \mathrm{HSE}: \mathrm{EGFP})$ line. The EGFP+ frequency of F2 offspring reached to $75 \%$ after heat shocked.

\section{RUNX1-Evi-1 induced immature hematopoietic cells emerged in blood circulation}

Using Wright Giemsa staining, peripheral blood from WT zebrafish at $60 \mathrm{dpf}$ contained clusters of erythrocytes, while myeloid cells were only occasionally observed (Fig. 3a). In contrast, the blood cells from the $\mathrm{Tg}(\mathrm{RE}: \mathrm{H}-$ SE:EGFP) fish contained some blast-like cells, which were larger than the erythrocytes and had high nuclear to cytoplasmic ratios with multiple large nucleoli. These cells resembled to human AML blasts. Meanwhile, erythrocytes were significantly inhibited (Fig. 3b). The similar feature presented in single cell suspensions of kidney from WT and Tg F2 generation (Fig. 2c-d).

\section{RUNX1-Evi-1 reprogrammed lineage-specific hematopoietic transcription factors}

Similar to mammalian, zebrafish also experienced a primitive wave and a definitive wave of hematopoiesis. From the 2 somite stage, cells co-expressing stem cells transcription factor (scl), gata2 and LIM only protein 2 (lmo2) transcription factors bilaterally appeared in both the anterior lateral mesoderm (ALM) and the posterior lateral mesoderm (PLM). They have the potential to become HSCs, but not kidney progenitors [20]. The expression of scl, lmo2, and gata2 were measured by qRT-PCR and in situ hybridization in WT and Tg(RE:HSE:EGFP) F2 generation embryos at $12 \mathrm{hpf}, 18 \mathrm{hpf}$ and $24 \mathrm{hpf}$. Scl was slight higher expression in Tg embryos than that in WT at 24hpf $(0.329 \pm 0.066$ vs $0.547 \pm 0.096, \mathrm{P}=0.032)$ (Fig. $4 \mathrm{a}, \mathrm{i}-\mathrm{j})$. No significant difference of $1 \mathrm{mo} 2$ expression between WT and Tg(RE:HSE:EGFP) zebrafish was identified (Fig. 4b, k-l). Gata2 was upregulated compared to WT counterpart at $18 \mathrm{hpf}(1.180 \pm 0.075$ vs $1.426 \pm 0.066, \mathrm{P}=0.013)$ and $24 \mathrm{hpf}$ $(1.211 \pm 0.045$ vs $1.965 \pm 0.144, \mathrm{P}=0.001)$ (Fig. $4 \mathrm{c}, \mathrm{m}-\mathrm{n})$.

Gata1 and pu.1 is the master regulator in erythrocyte and myeloid cell development involved in primitive hematopoiesis, respectively. In zebrafish, gata1 is expressed from the 5 somite stage in the PLM. According to the results in WT and Tg embryos at $1 \mathrm{dpf}(1.114 \pm 0.126 \mathrm{vs}$ $0.493 \pm 0.097), 3 \mathrm{dpf}(1.674 \pm 0.237$ vs $1.308 \pm 0.236), 7$ $\operatorname{dpf}(2.565 \pm 0.321$ vs $1.863 \pm 0.192)$, and $60 \mathrm{dpf}(5.496 \pm$ 0.470 vs $2.573 \pm 0.328$ ). It was demonstrated that the levels of gata1 significantly decreased in $\mathrm{Tg}$ embryos (Fig. 4d, o-p). Pu.1 is expressed from the 6 somite stage in the ALM. Compared with WT, its expression was upregulated in $\mathrm{Tg}$ groups at $3 \mathrm{dpf}(1.274 \pm 0.165$ vs $1.702 \pm$ $0.155)$ and $7 \mathrm{dpf}(2.432 \pm 0.540$ vs $3.496 \pm 0.367)$ (Fig. 4e).

Like in mammals, the first definitive HSCs of zebrafish arise from the ventral region of the dorsal aorta, and express runx 1 and $\mathrm{c}$-myb transcription factors. Unlike primitive HSCs, definitive HSCs have the potential to become all blood lineages including lymphocytes. Runx1

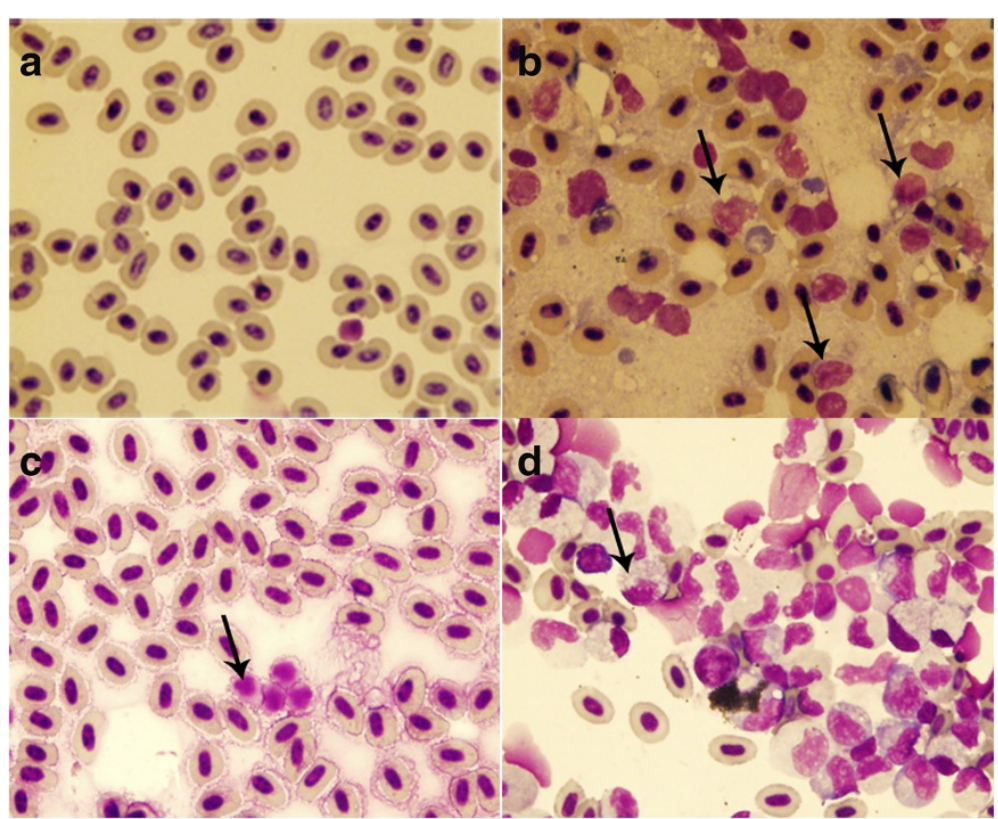

Fig. 3 Cytological analysis of Tg(RE:HSE:EGFP) zebrafish. Cytology of hematopoietic cells from WT (a) and Tg(RE:HSE:EGFP) F2 generation (b) zebrafish at $60 \mathrm{dpf}$. The blood cells from WT fish were predominantly erythrocytes, and by contrast, erythrocytes were significantly inhibited in $\operatorname{Tg}($ RE:HSE:EGFP) fish, enriched for abundant blast-like cells, which are larger than the erythrocytes and have high nuclear to cytoplasmic ratios, containing multiple large nucleoli (black arrow). These blasts were similar to that of human AML peripheral blood. The similar feature presented in single cell suspensions of kidneys from WT (c) and Tg F2 generation (d) 


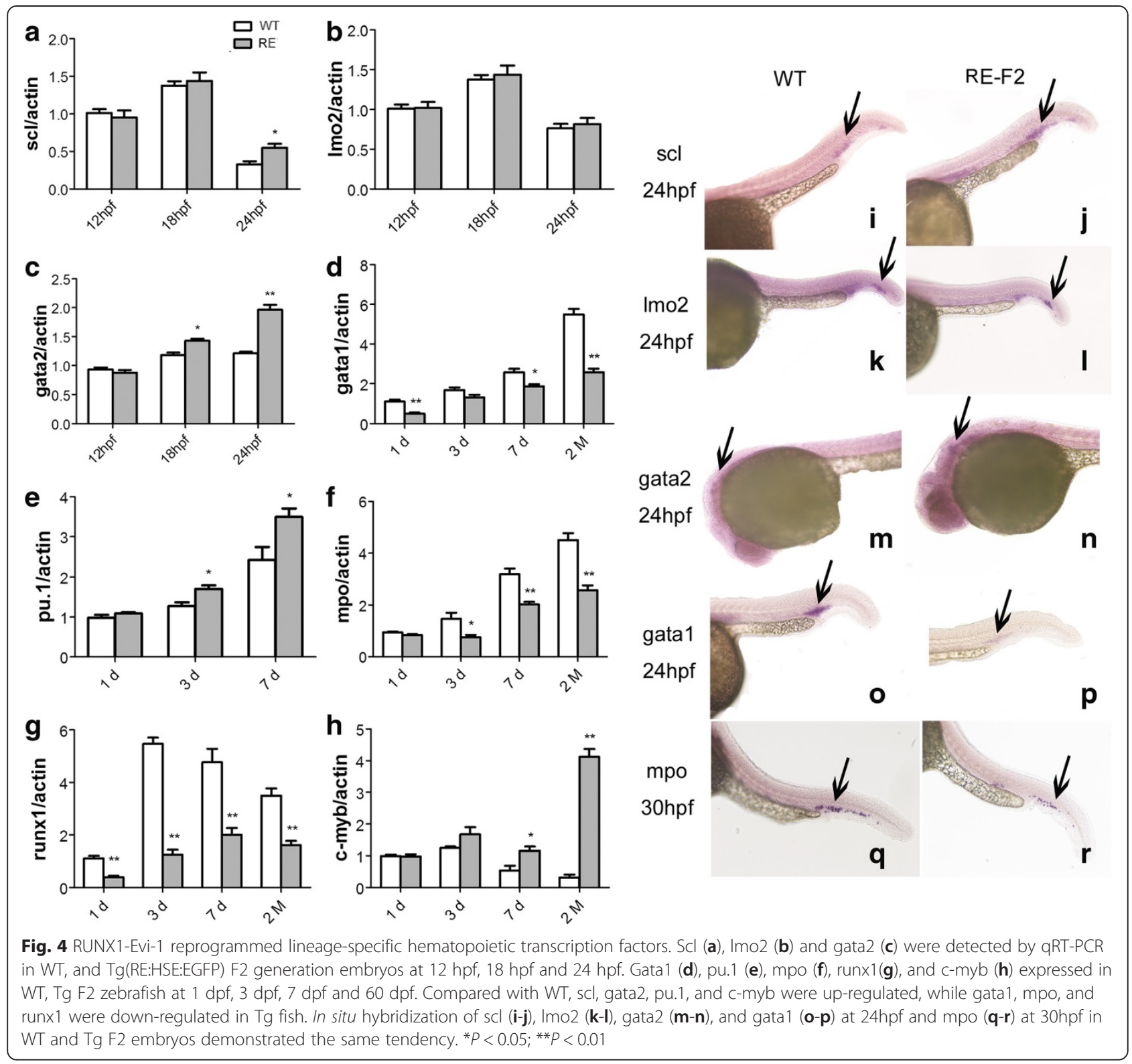

were dramatically downregulated in $\mathrm{Tg}$ (RE:HSE:EGFP) embryos at $1 \mathrm{dpf}(1.114 \pm 0.156$ vs $0.393 \pm 0.099), 3 \mathrm{dpf}$ $(5.474 \pm 0.402$ vs $1.256 \pm 0.296), 7 \mathrm{dpf}(4.765 \pm 0.892$ vs $1.996 \pm 0.470)$, and $60 \mathrm{dpf}(3.496 \pm 0.470$ vs $1.609 \pm 0.274)$ (Fig. 4g). Whereas, the expression of c-myb, whose expression is predominantly present in immature hematopoietic cells and decreases during cell differentiation, did not decrease with cell growth and differentiation in $\mathrm{Tg}$ fish at $60 \mathrm{dpf}(0.314 \pm 0.158$ vs $4.122 \pm 0.419, \mathrm{P}=0.000)$ (Fig. 4h). It was indicative of a large number of immature blood cells accumulating in blood circulation.

As the downstream gene of pu.1, myeloperoxidase (mpo) was the granulocyte specific gene and considered as the symbol of mature neutrophils, whose expression was firstly detected in between 18 and $20 \mathrm{hpf}$ with the distribution from the intermediate cell mass (ICM) to rostral blood island (RBI). In Tg fish, the mpo expression obviously reduced at $3 \mathrm{dpf}(1.474 \pm 0.402$ vs $0.753 \pm$ $0.158), 7 \mathrm{dpf}(3.199 \pm 0.373$ vs $2.029 \pm 0.173)$, and $60 \mathrm{dpf}$ $(4.496 \pm 0.470$ vs $2.576 \pm 0.325)$ (Fig. 4f, q-r). It's not enough to support the myeloid cells' further development and differentiation.

\section{RUNX1-Evi-1 changed multiple transcriptional pathways in transgenic larvae}

Using Agilent microarray analysis, we obtained a total of 578 DEGs in the blood cells of Tg(RE:HSE:EGFP) F2 generation $v s$ WT larvae at 3dpf. There were 348 genes upregulated and 230 genes downregulated (2-fold change in expression, $P<0.01)$. Analyzed by NIH-DAVID 
software, several KEGG pathways were significantly enriched $(P<0.01$, Benjamini $<0.01)$ (Table 2) (GSE74944).

Some signaling pathways were upregulated in the $\operatorname{Tg}($ RE:HSE:EGFP) fish, including proteasome, cell cycle, glycolysis/gluconeogenesis, tyrosine metabolism, tryptophan metabolism, metabolism of xenobiotics by cytochrome P450, PPAR signaling pathway, etc. Glycolysis was often depended on for ATP production in rapidly proliferating tumors even in normoxia, which is defined as the Warburg effect. Here, RUNX1-Evi-1 also significantly upregulated the genes that correlated with glycolysis/gluconeogenesis ( $\mathrm{n}=16, \mathrm{P}=8.5 \mathrm{E}-6)$, including fructose1, 6-bisphosphatase I, glucose-6-phosphate 1-epimerase, and glucose-6-phosphate isomerase.

Meanwhile, transforming growth factor $\beta$ (TGF $\beta$ ), JakSTAT, DNA replication, mismatch repair, p53 pathway, JUN N-terminal kinase (JNK) signaling pathway, nucleotide excision repair were downregulated. JNKs belong to the superfamily of mitogen-activated protein kinases that are involved in the regulation of cell proliferation, differentiation and apoptosis [21]. Compared with WT, some crucial genes were downregulated in Tg samples $(n=7$,
$\mathrm{P}=6.8 \mathrm{E}-4$, Fig. 5). The proteins of JNKs and p-JNKs (the activated state) dramatically decreased in $\mathrm{Tg}(\mathrm{RE}: \mathrm{H}-$ SE:EGFP) F2 larvae (Fig. 5).

Majority of the above pathway alterations were associated with human hematopoietic disorders and malignant transformation of blood cells [22-26]. These data needs to be verified in further experiments.

\section{VPA partially rescued some pathways abnormally regulated by RUNX1-Evi-1}

Mitani found that RUNX1-related chimeras generated by the chromosomal translocations repress transcriptional activity of wild-type RUNX1 (AML1) by recruiting the corepressor/histone deacetylase complex in leukemia cell lines. Further, as a histone deacetylase inhibitors(HDACi), VPA could elicit apoptosis through both extrinsic and intrinsic pathways in these cells [27]. Here, microarray analysis also showed that histone deacetylase 4 (hdac4) was significantly upregulated in $\mathrm{Tg}$ (RE:HSE:EGFP) F2 generation larvae (6.18 vs 10.62, fold change: 21.70 , showed in Table 3). Therefore, we investigated the in vivo effects of VPA on $\operatorname{Tg}($ RE:HSE:EGFP) zebrafish.

Table 2 Change of signaling pathways in Tg(RE:HSE:EGFP) zebrafish

\begin{tabular}{|c|c|c|c|c|c|}
\hline Term & Regulate & Count $^{a}$ & $\%^{b}$ & $P$-Value & Benjamini \\
\hline Proteasome & + & 11 & 1.3 & $2.6 \mathrm{E}-9$ & $2.8 \mathrm{E}-7$ \\
\hline Cell cycle & + & 28 & 2.2 & $5.3 \mathrm{E}-8$ & $3.7 \mathrm{E}-6$ \\
\hline Glycolysis/Gluconeogenesis & + & 16 & 1.0 & $8.5 \mathrm{E}-6$ & $7.0 \mathrm{E}-5$ \\
\hline Tyrosine metabolism & + & 10 & 0.9 & $9.1 \mathrm{E}-6$ & $3.9 \mathrm{E}-5$ \\
\hline Tryptophan metabolism & + & 8 & 0.9 & $1.6 \mathrm{E}-5$ & 4.1E-4 \\
\hline Drug metabolism & + & 7 & 0.8 & $5.1 \mathrm{E}-5$ & $7.6 \mathrm{E}-3$ \\
\hline Metabolism of xenobiotics by cytochrome P450 & + & 7 & 0.8 & $5.1 \mathrm{E}-3$ & 7.6E-2 \\
\hline Androgen and estrogen metabolism & + & 8 & 0.9 & 7.0E-3 & $8.0 \mathrm{E}-2$ \\
\hline PPAR signaling pathway & + & 6 & 0.7 & $7.2 \mathrm{E}-3$ & $7.4 \mathrm{E}-2$ \\
\hline Retinol metabolism & + & 4 & 0.5 & $8.4 \mathrm{E}-3$ & $7.5 \mathrm{E}-2$ \\
\hline Jak-STAT signaling pathway & - & 14 & 2.4 & $6.8 \mathrm{E}-10$ & $8.3 \mathrm{E}-8$ \\
\hline DNA replication & - & 15 & 1.1 & $3.5 E-9$ & $3.0 \mathrm{E}-7$ \\
\hline Mismatch repair & - & 8 & 0.9 & $4.5 \mathrm{E}-7$ & $1.8 \mathrm{E}-6$ \\
\hline Homologous recombination & - & 12 & 0.9 & $8.9 \mathrm{E}-7$ & $3.5 \mathrm{E}-5$ \\
\hline Base excision repair & - & 12 & 1 & 2.7E-6 & 4.7E-5 \\
\hline Spliceosome & - & 22 & 1.6 & $2.9 \mathrm{E}-5$ & 4.4E-4 \\
\hline Nucleotide excision repair & - & 18 & 1.2 & $6.3 \mathrm{E}-5$ & $4.3 \mathrm{E}-4$ \\
\hline p53 signaling pathway & - & 16 & 1.3 & $3.8 \mathrm{E}-4$ & $8.3 \mathrm{E}-3$ \\
\hline JNK signaling pathway & - & 7 & 1.2 & 4.0E-4 & 8.7E-3 \\
\hline Butanoate metabolism & - & 4 & 0.7 & 4.1E-4 & $2.7 \mathrm{E}-3$ \\
\hline Transforming growth factor $\beta$ & - & 14 & 1.1 & $6.3 \mathrm{E}-4$ & $7.3 \mathrm{E}-3$ \\
\hline Porphyrin and chlorophyll metabolism & - & 4 & 0.7 & $7.4 \mathrm{E}-4$ & $7.8 \mathrm{E}-3$ \\
\hline Arginine and proline metabolism & - & 5 & 0.9 & $7.8 \mathrm{E}-4$ & $8.0 \mathrm{E}-3$ \\
\hline
\end{tabular}

+: upregulated; -: downregulated. ${ }^{a}$ : genes involved in the term. ${ }^{\mathrm{b}}$ : involved genes/total genes

$P$-Value: the threshold of EASE Score, a modified Fisher Exact P-Value, for gene-enrichment analysis $(<0.01)$. Benjamini: Benjamini and Hochberg's false discovery rate $(<0.01)$ 


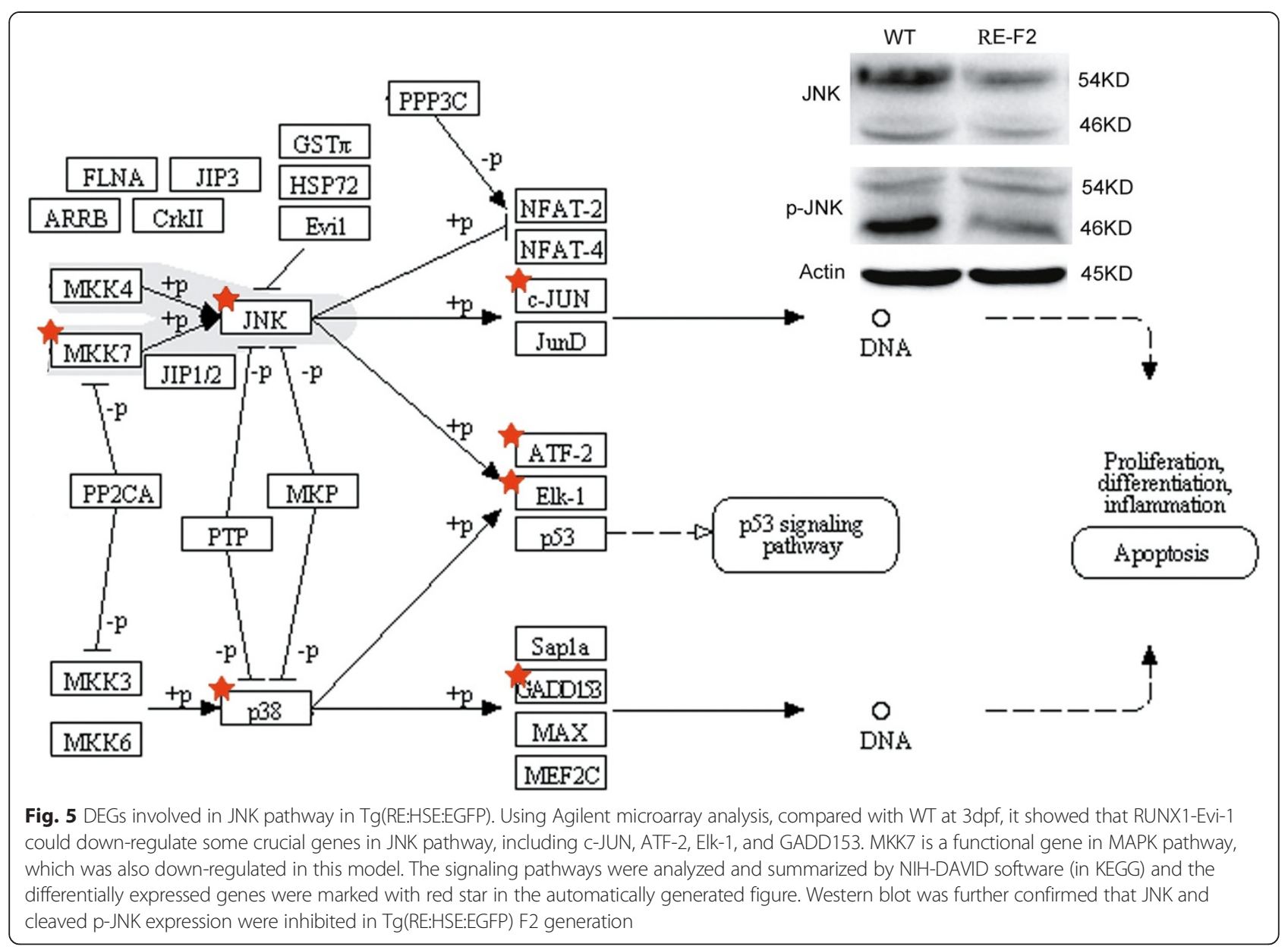

$\mathrm{Tg}$ (RE:HSE:EGFP) embryos were treated with different concentrations of VPA at $28{ }^{\circ} \mathrm{C}$ from 14 hpf after one hour of heat shock treatment. According to the outcome at 72hpf $[\mathrm{Y}=29.18 \ln (\mathrm{x})+0.49(0.9799)]$, we got the LD50 as $69.72 \mu \mathrm{M}$, and chose $35 \mu \mathrm{M}, 70 \mu \mathrm{M}$ to carry on detecting the effectiveness. By FCM analysis, elevated apoptosis was presented in VPA treated groups, which was indicated by sub G1 peak. Compared with the untreated group, treated with $70 \mu \mathrm{M}$ VPA induced apoptosis at $(60.43 \pm 7.28) \%$ and decreased S/G2 cell population at $[(87.37 \pm 4.06) \%$ vs $(23.64 \pm 3.23) \%, P<0.01]$, correspondingly, G1 arrest was increased.

Furthermore, we measured the expression of some crucial factors involved in proliferation and apoptosis

Table 3 RUNX1-Evi-1 upregulated histone deacetylase in microarray analysis

\begin{tabular}{lrrrl}
\hline Genes & WT & AE-F2 & FC & Regulation \\
\hline Histone deacetylase 11 (HD11) & 5.47 & 8.16 & 6.49 & + \\
Histone deacetylase 4 (hdac4) & 6.18 & 10.62 & 21.70 & + \\
H1 histone family, member X (h1fx) & 10.02 & 11.36 & 2.53 & + \\
\hline
\end{tabular}

FC: fold change; + : upregulated pathways after treated with different concentrations of VPA by qRT-PCR (Fig. 7). It showed that VPA reduced the expression of skp2 and upregulated p21, p27, which would inhibit the progress of cell proliferation. Smad7 was also inhibited by VPA and revived the TGF $\beta$ signaling. VPA significantly downregulated $\mathrm{Bcl} 2$, but enhanced the expression of P53, Bax, JNK and JUN, which indicated the activation of both extrinsic and intrinsic apoptosis. Majority change of these genes was concentration dependence (Fig. 7). In contrast, the expression of the above genes showed no significant difference in wild type zebrafish embryos treated with the similar dose of VPA (data not shown).

\section{Followed-up of the transgenic zebrafish}

Different from 3 years lifetime of the WT zebrafish, all these three F0 founders died within 8-14 months (median: 10.6 months). Most of the F1 and F2 generation gradually lost the EGFP expression and the ability of fecundity, and began to die older than 12 months. Along with the growth of $\mathrm{Tg}$ (RE:HSE:EGFP) zebrafish, some of them presented pathological appearance (e.g. hemorrhage, edema and small size) (Fig. 8). 


\section{Discussion}

Growing evidences demonstrated that normal function loss of Runx1/AML1 or abnormal activation of Evi-1 was an indicator of poor prognosis in leukemia [27-29]. It was also shared that RUNX1-Evi-1 fusion gene could enhance the malignant effectiveness [30]. Nevertheless, the major mechanism of RUNX1-Evi-1 exerts in acute leukemia and whether it possesses the whole role of Evi-
1 remained widely unknown. We reported here an RUNX1-Evi-1 transgenic zebrafish model with a phenotype that recapitulated main aspects of human AML such as distorted proliferation, anti-apoptosis, anemia, increased immature myeloid cells and their precursors accumulated in peripheral circulation and kidney marrow (kidney marrow serves throughout the life of a zebrafish, generating adult hematopoietic cells, just like human's

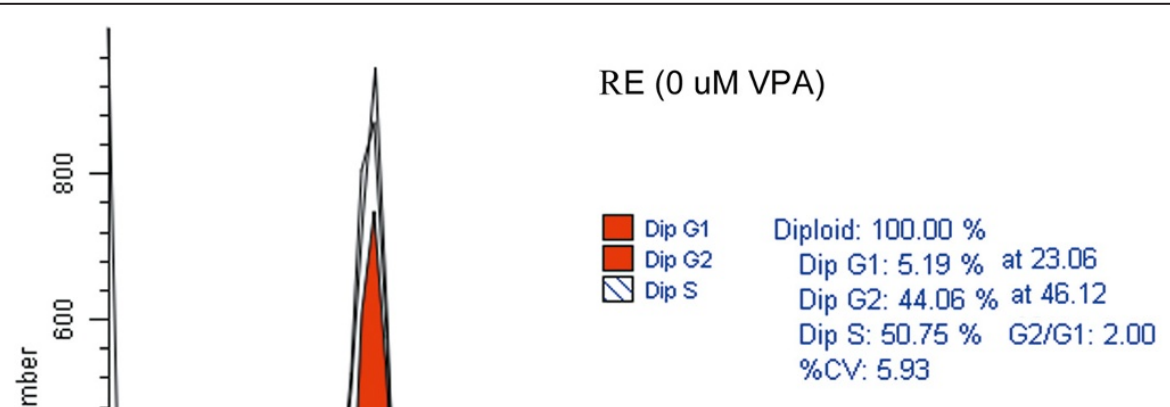

Total S-Phase: $50.75 \%$
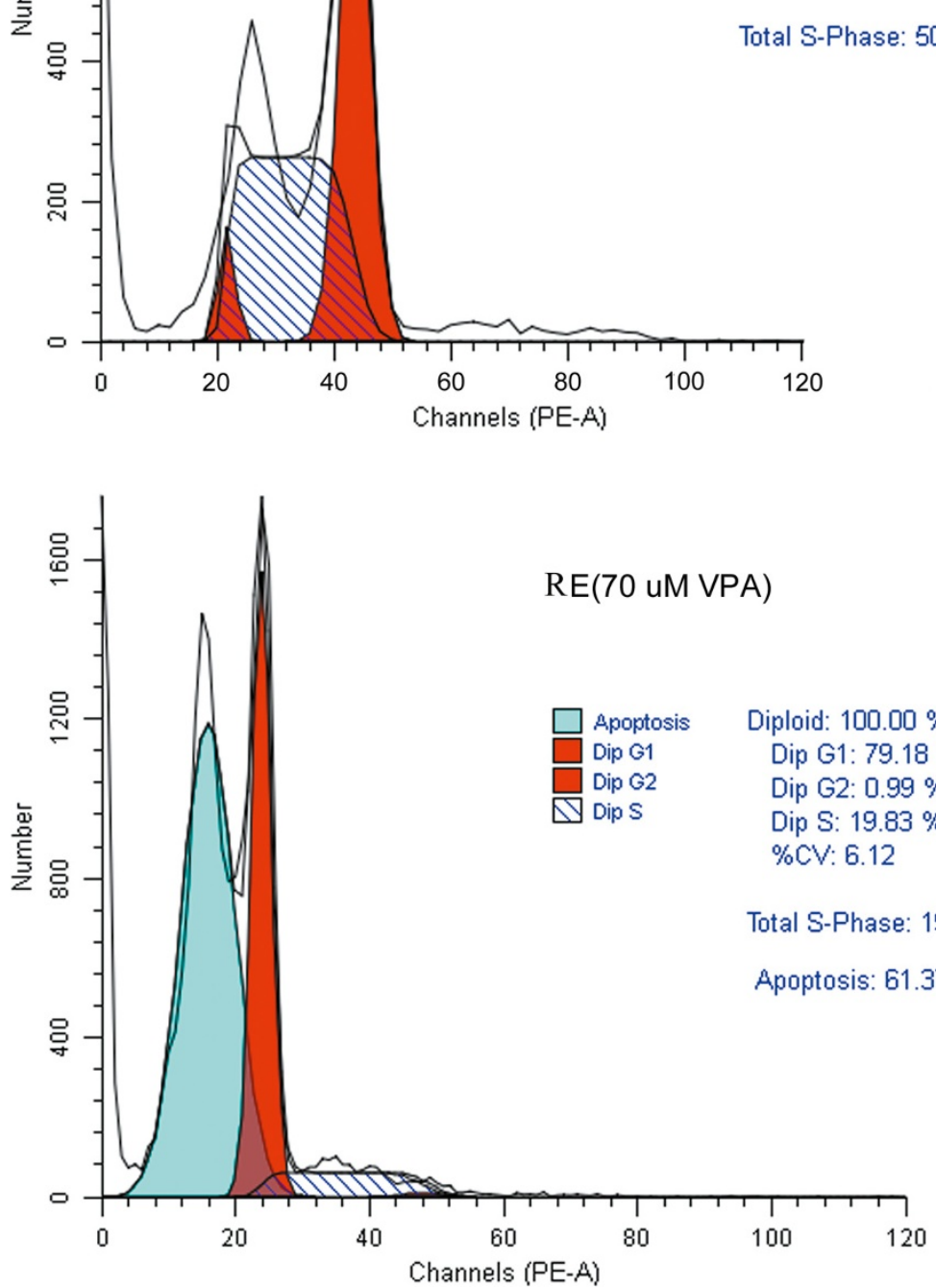

Fig. 6 VPA promoted the G1 arrest and apoptosis in RUNX1-Evi-1 positive cells. The cells of Tg(RE:HSE:EGFP) embryos were sorted with GFP after two days treated by $70 \mu \mathrm{M}$ VPA. The ratio of S/G2 phase was sharply decreased (94.81 \% vs $20.82 \%$ ), accompanied with a sub-G1 peak (61.37 \%) 
bone marrow [20]), which suggested that RUNX1-Evi-1 played a role in the etiology of AML. More importantly, zebrafish offers the advantage of high-throughput scale in the study of RUNX1-Evi-1 function and drug screen in vivo, which enables us to track the molecular alterations that occur well before the appearance of morphological phenotypes, and to determine the roles of candidate RUNX1-Evi-1 target genes.

HSP has no tissue-specific preference, yet heat stress exhibits more direct and far-reaching influence on white blood cells than other cells. Moreover, RUNX1-Evi-1 overexpression is highly oncogenic in myeloid cells. Thus, the establishment of RUNX1-Evi-1 transgenic zebrafish with the uniform phenotype of the tumor cells shows better resemblance to the feature of human MDS/AML.

Carolyn [28] found disruption of terminal myeloid differentiation and cell cycle regulation to be prominent in Evi-1-induced leukemogenesis. Using microarray analysis, we also found the upregulation of cell cycle $(n=28$, $\mathrm{P}=5.3 \mathrm{E}-8)$ and repression of TGF- $\beta$ signaling $(\mathrm{n}=14$, $\mathrm{P}=6.3 \mathrm{E}-4)$ in $\operatorname{Tg}(\mathrm{RE}: \mathrm{HSE}: \mathrm{EGFP})$ zebrafish, accompanied by increased expression of some early hematopoiesis transcription factors (gata2 and pu.1) (Fig. 4c, e, m-n). Gata2 was a zinc finger transcription factor which was required for proliferation and maintenance of hematopoietic progenitor cells [20]. Yuasa [31] showed that Evi-1 promoted early hematopoietic development in the P-Sp region, which seemed to depend on activation of gata2 and repression of TGF- $\beta$ signaling, while ZF1 of Evi-1 directly recognized and banded to the gata2 promoter. Gata2 has been reported to be aberrantly expressed in $87 \%$ of de novo AML cases while well correlation between Evi-1 and gata2 expression were found in AML patients [28, 32]. Thus, it's feasible that gata2 plays a crucial role in RUNX1-Evi-1 or Evi-1-induced leukemogenesis. Likewise, Evi-1 interacted with pu.1 and repressed the pu.1dependent activation of a myeloid promoter [21]. Leopoldo [21] reported on a mouse model that constitutive expression of Evi-1 in the BM led to fatal anemia and myeloid dysplasia, and Evi-1 interaction with gata1 blocks proper erythropoiesis. Here, RUNX1-Evi-1 slightly enhanced the expression of pu.1, but repressed the level of mpo, the downstream regulator of pu.1 (Fig. 4e-f, q-r).

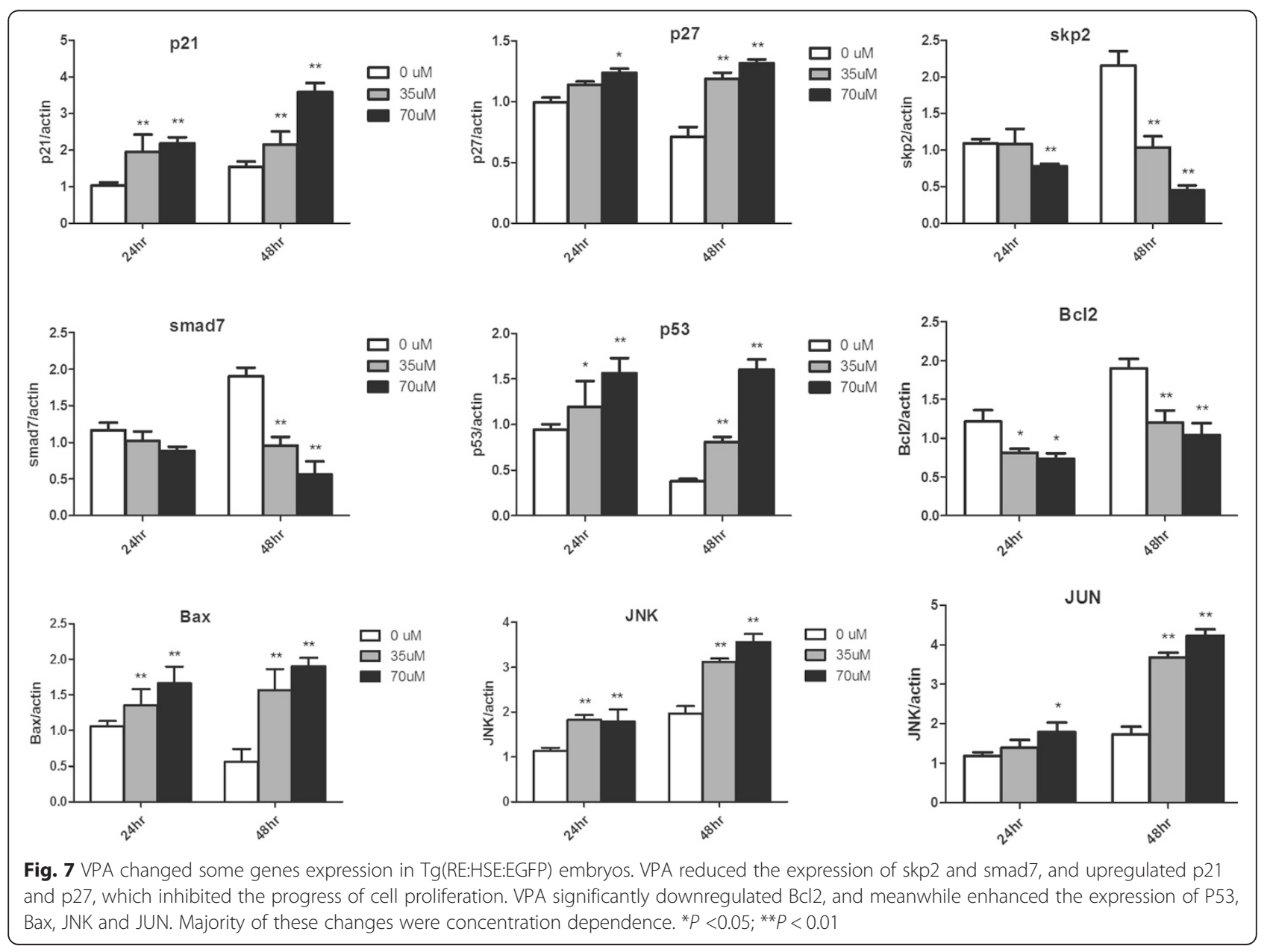


Meanwhile, gata1, the indispensable promoter for erythropoiesis, was overwhelmingly inhibited along with growth (Fig. 4d, o-p). Actually, there was a cross-inhibitory mechanism between the expression of gata1 and pu.1 in zebrafish [20], which indicated that the level of pu.1 expression was determined by the ability of RUNX1-Evi-1 to regulate both pu.1 and gata1, thus increased the repopulation of immature myeloid cells and anemia.

Evi-1 was a zinc finger-containing and site specific DNA-binding transcription factor, but it did not seem to inhibit pu.1 binding to DNA, but rather to block its association with the co-activator JNK and its substrates [21]. In response to cell death stimuli, p-JNKs activated apoptotic signaling by regulating apoptotic-associated genes via the transcriptional activation of specific transcription factors or by directly modulating the activities of mitochondrial apoptosis-associated proteins through distinct phosphorylation events [24]. In our previous work, we demonstrated that arsenic trioxide (ATO) could reactivate apoptosis in the THP1 (with high level of Evi-1 expression) cell line by downregulating Evi-1. ATO significantly decreased Bcl-2 and Bcl-xL expression, thus accordingly increased the levels of JNK, pJNK, Bax, full length caspase-3 and cleaved caspase-3 in western blot analysis [33]. In the present study, RUNX1Evi-1 fusion gene inhibited both JNK signaling and P53 pathway (Table 2). Using FCM, we found that more than $50 \%$ of RUNX1-Evi-1 positive cells were in the S/G2 period and no sub-G1 peak (Fig. 6), which demonstrate apoptosis resistant and weak efficacy of G1 arrest. Because of the deficiency of enough monoclonal antibody for zebrafish and lethal effectiveness of RUNX1-Evi-1 to mouse embryos [34], we plan to do further study on the efficacy of ATO in Tg(RE:HSE:EGFP) zebrafish and confirm molecular mechanism in detail through retroviral transduction of RUNX1-Evi-1 into Evi-1 negative cell lines or adult mice.

RUNX1-related chimeras generated by the chromosomal translocations repressed transcriptional activity of wild-type RUNX1 by recruiting the co-repressor/histone deacetylase complex [27]. Thus, histone deacetylase inhibitors were expected to restore normal functions of wild-type RUNX1, and thereby affect the growth and differentiation ability of leukemic cells expressing the chimera. Histone deacetylase 4 obiously increased in $\mathrm{Tg}$ (RE:HSE:EGFP) larvae (Table 3). Therefore, we investigated the in vivo effects of histone deacetylase inhibitor (VPA). G1 arrest and apoptosis progression were significantly enhanced in RUNX1-Evi-1 positive cells after 2-day treated with VPA (Fig. 6). Up- and downregulation of cell cycle and apoptosis regulator genes appeared to be the molecular basis for the former (Fig. 7). Therefore, VPA may be an attractive choice in the molecular targeting therapy of RUNX1-Evi-1-related leukemia.
60 years ago, some scholars have presented that disordered amino acid metabolic processes in patients with acute leukemia, such as eighteen patients with acute leukemia averaged $137.1 \mathrm{mg}$. of urinary "tyrosyl" in $24 \mathrm{hr}$. as compared to $115.8 \mathrm{mg}$. for normal individuals of the same age group [35]. Tyrosine kinase inhibitors (TKIs) therapy in leukemia cells creates a novel metabolic state that is highly sensitive to particular mitochondrial perturbations [36]. The essential amino acid L-tryptophan (L-TRP) is required for the biosynthesis of proteins and is precursor for several biologically important compounds, and the inhibition level of L-TRP metabolites in blood could be a useful parameter of chemotherapy efficacy for Adult T-cell Leukemia/Lymphoma patients [37]. In contrary, the majority of newly diagnosed AML patients' blasts have deficiencies in the arginine-recycling pathway enzymes argininosuccinate synthase and ornithine transcarbamylase, making them arginine auxotrophic [38]. Miraki-Moud F et al. showed that AML cells from most patients with AML are deficient in a critical enzyme required for arginine synthesis, arginino succinate synthetase-1 (ASS1). Thus, these ASS1-deficient AML cells are dependent on importing extracellular arginine [39]. Using Agilent microarray analysis, we also found that tyrosine metabolism and tryptophan metabolism pathway were upregulated, while Arginine and proline metabolism

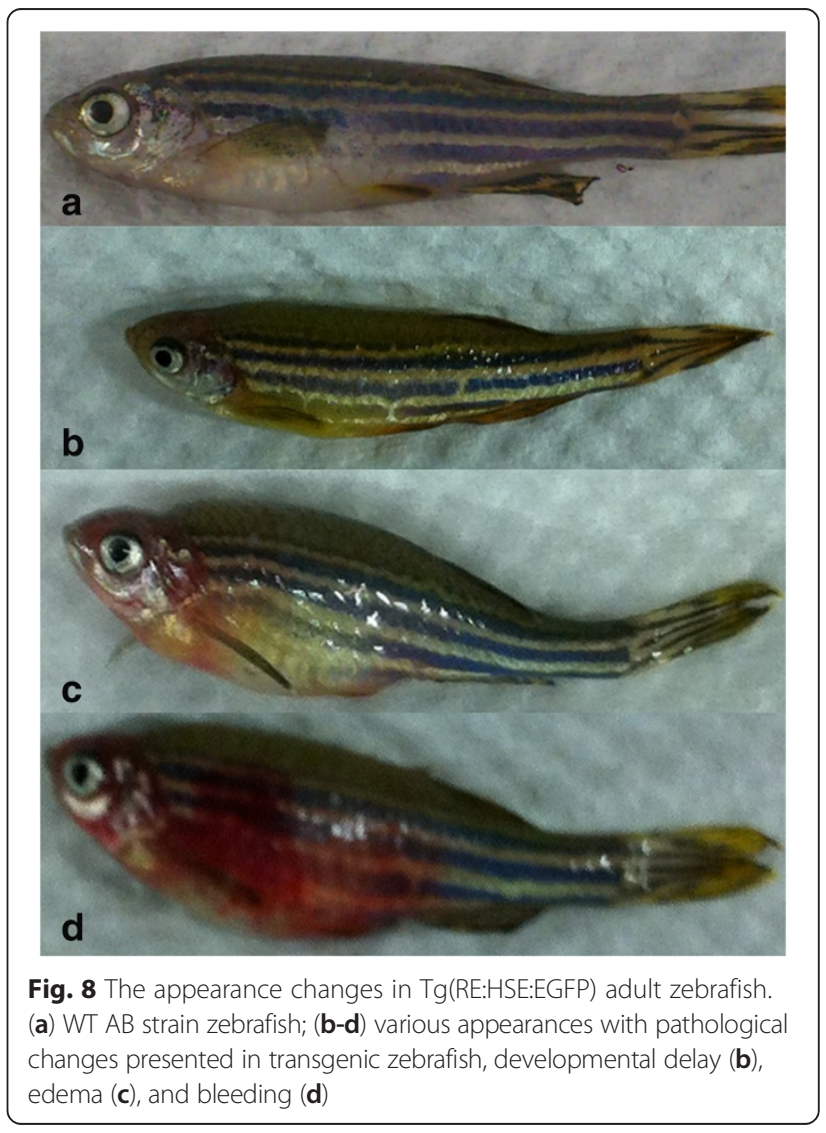


were inhibited in the $\mathrm{Tg}$ (RE:HSE:EGFP) F2 generation. It suggested that the strategy of enzymatic degradation of amino acids to deprive malignant cells of important nutrients would be an established component of induction therapy of AML.

Interestingly, Maki [34] knocked-in the RUNX1-Evi-1 chimeric gene into mouse embryo, which led to defective hematopoiesis in the fetal liver and death around embryonic day 13.5 (E13.5) as a result of hemorrhage in the central nervous system. Maki hypothesized that maintained expression of pu. 1 gene and decreased expression of $1 \mathrm{mo} 2$ and scl genes may explain the aberrant hematopoiesis. We also found that some of the $\operatorname{Tg}(\mathrm{RE}$ :HSE:EGFP) zebrafish died of hemorrhage (Fig. 8d). However, the levels of scl and $1 \mathrm{mo} 2$ expression were similar to those in WT counterpart and the average lifespan was nearly 12 months. Taking the advantage of transparence in zebrafish embryo, we performed whole-mount in situ hybridization to confirm the difference expression of these factors, which were consistent with the results of qRT-PCR. The different outcome between Maki's and ours may be associated with the different species, which needs further explore.

\section{Conclusion}

Taken together, the phenotypes of $\mathrm{Tg}(\mathrm{RE}: \mathrm{HSE}$ :EGFP) fish resemble to those of the human's MDS-RAEB or AML. RUNX1-Evi-1 promoted the primitive hematopoietic cell proliferation and apoptosis resistant, inhibited myeloid cells differentiation through synergy of several pathway and factors. This model provides a useful tool to conduct whole-organism chemical suppressor screens to identify compounds that can regain RUNX1 function and reverse Evi-1 in vivo. We propose VPA to be an attractive choice in the molecular targeting therapy of RUNX1-Evi-1-related leukemia.

\footnotetext{
Abbreviations

AML: Acute myeloid leukemia; Evi: Ecotropic viral integration site; MDS: myelodysplastic syndrome; RHD: runt homology domain; IACUC: Institutional Animal Care and Use Committee; pA: polyadenylation; hpf or dpf: hours or days post fertilization; WT: wild type; Tg: transgenic; GRT-PCR: Real-time quantitative reverse transcription PCR; Ct: cycle threshold; KEGG: Kyoto Encyclopedia of Genes and Genomes; DEGs: differentially expressed genes; PBS: phosphate-buffered saline; ALM: anterior lateral mesoderm; PLM: posterior lateral mesoderm; scl: stem cells transcription factor; Imo2: LIM only protein 2; mpo: myeloperoxidase; ICM: intermediate cell mass; RBI: rostral blood island; TGF $\beta$ : transforming growth factor $\beta$; JNK: JUN N-terminal kinase; hdac4: histone deacetylase 4; VPA: valproic acid; ATO: arsenic trioxide
}

\section{Competing interests}

The authors declare no competing interests.

\section{Authors' contributions}

LS cloned the plasmid and established the transgenic zebrafish, analyzed the data, and wrote the manuscript; FC designed and supervised the research; JZ and WL carried out the molecular genetic studies, in situ hybridization, and FACS profile analysis; JC and JZ participated in cytological analysis and drug treatment; $\mathrm{HZ}$ participated in microarray analysis. All the authors read and approved the final manuscript.

\section{Acknowledgments}

We thank all members of Shanghai Research Center for Biomodel Organisms and the Shanghai Institute of Hematology for excellent technical support. We are grateful to Prof. Czerny T and Grosveld GC for offering PSGH2 vector and PME-AE plasmid.

This work was supported in part by National Natural Science Foundation of China Grant (81470312 and 81300405), Science and Technology Commission of Shanghai Fund Project of TCM guide project (12401906700), Seed Fund Project of Scientific Research of Renji Hospital (RJZZ12-007), and Shanghai health and planning committee (no.201440369).

\section{Author details}

'Department of Hematology, Ren Ji Hospital, School of Medicine, Shanghai Jiao Tong University, Shanghai 200127, China. 'Department of Hematology, Ren Ji Hospital, School of Medicine, Shanghai Jiao Tong University, 160 Pujian Road, Shanghai, China.

Received: 28 March 2015 Accepted: 30 November 2015 Published online: 16 December 2015

\section{References}

1. Harada H, Harada Y, Niimi H, Kyo T, Kimura A, Inaba T. High incidence of somatic mutations in the AML1/RUNX1 gene in myelodysplastic syndrome and low blast percentage myeloid leukemia with myelodysplasia. Blood. 2004;103(6):2316-24.

2. Lugthart $S$, van Drunen $E$, van Norden $Y$, van Hoven A, Erpelinck CA, Valk PJ, et al. High EVI1 levels predict adverse outcome in acute myeloid leukemia: prevalence of EVI1 overexpression and chromosome $3 q 26$ abnormalities underestimated. Blood. 2008;111(8):4329-37.

3. Cuenco GM, Ren R. Both AML1 and EVI1 oncogenic components are required for the cooperation of AML1/MDS1/EVI1 with BCR/ABL in the induction of acute myelogenous leukemia in mice. Oncogene. 2004;23(2):569-79.

4. Ichikawa M, Asai T, Saito T, Seo S, Yamazaki I, Yamagata T, et al. AML-1 is required for megakaryocytic maturation and lymphocytic differentiation, but not for maintenance of hematopoietic stem cells in adult hematopoiesis. Nature medicine. 2004;10(3):299-304.

5. Takeshita M, Ichikawa M, Nitta E, Goyama S, Asai T, Ogawa S, et al. AML1-Evi-1 specifically transforms hematopoietic stem cells through fusion of the entire Evi-1 sequence to AML1. Leukemia. 2008;22(6):1241-9.

6. Cuenco GM, Nucifora G, Ren R. Human AML1/MDS1/EVI1 fusion protein induces an acute myelogenous leukemia (AML) in mice: a model for human AML. Proc Natl Acad Sci U S A. 2000;97(4):1760-5.

7. Watanabe-Okochi N, Kitaura J, Ono R, Harada H, Harada Y, Komeno Y, et al. AML1 mutations induced MDS and MDS/AML in a mouse BMT model. Blood. 2008;111(8):4297-308.

8. Goessling W, North TE. Hematopoietic Stem Cell Development: Using the Zebrafish to Identify the Signaling Networks and Physical Forces Regulating Hematopoiesis. Method Cell Biol Method Cell Biol. 2011;105:117-36.

9. Jing LL, Zon LI. Zebrafish as a model for normal and malignant hematopoiesis. Dis Model Mech. 2011;4(4):433-8.

10. Bajoghli B, Aghaallaei N, Heimbucher T, Czerny T. An artificial promoter construct for heat-inducible misexpression during fish embryogenesis. Developmental biology. 2004;271(2):416-30.

11. Westerfield M. The zebrafish book: a guide for the laboratory use of zebrafish (Danio rerio) 4th ed. Eugene (Oregon): University of Oregon Press; 2000.

12. Shen LJ, Chen FY, Zhang Y, Cao LF, Kuang Y, Zhong M, et al. MYCN transgenic zebrafish model with the characterization of acute myeloid leukemia and altered hematopoiesis. PloS one. 2013;8(3), e59070.

13. Livak KJ, Schmittgen TD. Analysis of relative gene expression data using real-time quantitative PCR and the 2(-Delta Delta C(T)) Method. Methods. 2001;25(4):402-8.

14. Link V, Shevchenko A, Heisenberg CP. Proteomics of early zebrafish embryos. BMC developmental biology. 2006;6:1.

15. Shen $L$, Cao LF, Chen FY, Zhang $Y$, Zhong JH, Zhong $H$. Using modified whole-mount hybridization to study expression in zebrafish. Experimental and therapeutic medicine. 2013;5(4):1043-7.

16. Jagadeeswaran P, Sheehan JP, Craig FE, Troyer D. Identification and characterization of zebrafish thrombocytes. British journal of haematology. 1999;107(4):731-8. 
17. Rowley AF, Hill DJ, Ray CE, Munro R. Haemostasis in fish-an evolutionary perspective. Thrombosis and haemostasis. 1997;77(2):227-33.

18. da Huang W, Sherman BT, Lempicki RA. Systematic and integrative analysis of large gene lists using DAVID bioinformatics resources. Nature protocols. 2009;4(1):44-57.

19. Lin C, Wu M, Dong J. Quercetin-4'-O-beta-D-glucopyranoside (QODG) inhibits angiogenesis by suppressing VEGFR2-mediated signaling in zebrafish and endothelial cells. PloS one. 2012;7(2):e31708.

20. Paik EJ, Zon LI. Hematopoietic development in the zebrafish. The International journal of developmental biology. 2010;54(6-7):1127-37.

21. Laricchia-Robbio L, Premanand K, Rinaldi CR, Nucifora G. EVI1 Impairs myelopoiesis by deregulation of PU.1 function. Cancer Res. 2009;69(4):1633-42.

22. Crawford LJ, Chan ET, Aujay M, Holyoake TL, Melo JV, Jorgensen HG, et al. Synergistic effects of proteasome inhibitor carfilzomib in combination with tyrosine kinase inhibitors in imatinib-sensitive and -resistant chronic myeloid leukemia models. Oncogenesis. 2014;3:e90.

23. Kojima K. The role of p53 in leukemia. [Rinsho ketsueki] The Japanese journal of clinical hematology. 2014;55(10):1724-30.

24. Chen YJ, Chang LS. Simvastatin induces NFkappaB/p65 down-regulation and JNK1/C-Jun/ATF-2 activation, leading to matrix metalloproteinase-9 (MMP-9) but not MMP-2 down-regulation in human leukemia cells. Biochemical pharmacology. 2014;92(4):530-43.

25. Pemmaraju N, Kantariian H, Kadia T, Cortes J, Borthakur G, Newberry K, et al. A Phase I/II Study of the Janus Kinase (JAK)1 and 2 Inhibitor Ruxolitinib in Patients With Relapsed or Refractory Acute Myeloid Leukemia. Clin Lymphoma Myeloma Leuk. 2014;15(3):171-6.

26. Pehlivan M, Sahin HH, Pehlivan S, Ozdilli K, Kaynar L, Oguz FS, et al. Prognostic importance of single-nucleotide polymorphisms in IL-6, IL-10, TGF-beta1, IFN-gamma, and TNF-alpha genes in chronic phase chronic myeloid leukemia. Genetic testing and molecular biomarkers. 2014;18(6):403-9.

27. Sasaki K, Yamagata T, Mitani K. Histone deacetylase inhibitors trichostatin A and valproic acid circumvent apoptosis in human leukemic cells expressing the RUNX1 chimera. Cancer science. 2008;99(2):414-22.

28. Glass C, Wuertzer C, Cui X, Bi Y, Davuluri R, Xiao YY, et al. Global Identification of EVI1 Target Genes in Acute Myeloid Leukemia. PloS one. 2013:8(6):e67134

29. Kumano K, Kurokawa M. The role of Runx1/AML1 and Evi-1 in the regulation of hematopoietic stem cells. Journal of cellular physiology. 2010;222(2):282-5

30. Mitani K. Molecular mechanisms of leukemogenesis by AML1/EVI-1. Oncogene. 2004;23(24):4263-9.

31. Yuasa H, Oike Y, Iwama A, Nishikata I, Sugiyama D, Perkins A, et al. Oncogenic transcription factor Evi1 regulates hematopoietic stem cell proliferation through GATA-2 expression. The EMBO journal. 2005;24(11):1976-87.

32. Shimamoto T, Ohyashiki JH, Ohyashiki K, Kawakubo K, Kimura N, Nakazawa S, et al. GATA-1, GATA-2, and stem cell leukemia gene expression in acute myeloid leukemia. Leukemia. 1994;8(7):1176-80.

33. Zhou LY, Chen FY, Shen LJ, Wan HX, Zhong JH. Arsenic trioxide induces apoptosis in the THP1 cell line by downregulating EVI-1. Experimental and therapeutic medicine. 2014:8(1):85-90

34. Maki K, Yamagata T, Asai T, Yamazaki I, Oda H, Hirai H, et al. Dysplastic definitive hematopoiesis in AML1/EVI1 knock-in embryos. Blood. 2005;106(6):2147-55

35. Waisman HA, Pastel RA, Poncher HG. Amino acid metabolism in patients with acute leukemia. Pediatrics. 1952;10(6):653-9.

36. Alvarez-Calderon F, Gregory MA, Pham-Danis C, DeRyckere D, Stevens BM Zaberezhnyy $\mathrm{V}$, et al. Tyrosine kinase inhibition in leukemia induces an altered metabolic state sensitive to mitochondrial perturbations. Clinical cancer research : an official journal of the American Association for Cancer Research. 2015;21(6):1360-72

37. Hoshi M, Ito H, Fujigaki $H$, Takemura M, Takahashi $T$, Tomita $\mathrm{E}$, et al. Changes in serum tryptophan catabolism as an indicator of disease activity in adult T-cell leukemia/lymphoma. Leukemia \& lymphoma. 2009;50(8):1372-4.

38. Mussai F, Egan S, Higginbotham-Jones J, Perry T, Beggs A, Odintsova E, et al. Arginine dependence of acute myeloid leukemia blast proliferation: a novel therapeutic target. Blood. 2015;125(15):2386-96.

39. Miraki-Moud F, Ghazaly E, Ariza-McNaughton L, Hodby KA, Clear A Anjos-Afonso F, et al. Arginine deprivation using pegylated arginine deiminase has activity against primary acute myeloid leukemia cells in vivo. Blood. 2015;125(26):4060-8.

\section{Submit your next manuscript to BioMed Central and we will help you at every step:}

- We accept pre-submission inquiries

- Our selector tool helps you to find the most relevant journal

- We provide round the clock customer support

- Convenient online submission

- Thorough peer review

- Inclusion in PubMed and all major indexing services

- Maximum visibility for your research

Submit your manuscript at www biomedcentral com/submit 